\title{
Discourse markers and L2 listening: do computers make a difference in $\mathrm{L} 2$ listening?
}

Nuray Alagözlü

Department of Foreign Language Teaching, Baskent University, Turkey

https://doi.org/10.36505/ExLing-2008/02/0001/000060

\begin{abstract}
This study explores whether discourse markers play a role in L2 listening comprehension and whether software programs make a difference in L2 listening comprehension. Two groups of approximately 25 freshman students listened to two versions of three different talks with and without higher order discourse markers. The talks were delivered by a native speaker, a non-native speaker and by a software listening program (NaturalReader(C) 7.0). The scorings, compared using the Mann-Whitney $U$ test, indicate that discourse markers play a significant role only in native speaker speech $(\mathrm{p}<0,05)$. It is seen that the highest mean of comprehension is found in the talks delivered by the native speaker. Computers ranked second in providing more comprehensive talks.
\end{abstract}

Key words: discourse markers, L2 listening comprehension

\section{Introduction}

Discourse structuring devices, specifically discourse markers (DMs), are of importance in the organization of texts, both spoken and written. Defined as "sequentially dependent elements" which bracket "units of talk" (Shiffrin, 1992), or "information units" (Brown and Yule, 1985), they work at different levels of the organization of the talk (Shiffrin, 1992). DMs are particular kinds of cohesive devices. With cohesion in discourse, the direction of ideas becomes transparent and their sequence flows easily, which is necessary for the interpretation of a text.

"Macro DMs" are the signalling markers which mark the boundaries between episodes and moves in talks; more precisely, They help the listener or reader recognize information units and organize them in his mind. They trigger readers' or listeners' predictions and expectations about the text (as you remember, our story doesn't end here, etc.). DMs which provide more opportunities for recognizing units at sentence and word level are called "micro DMs" (well, oh, because, etc.). The microstructure is associated fundamentally with a semantic, cohesive function holding between surface structure sentence (Chaudron and Richards, 1986).

In their study, Chaudron and Richards (1986) found that macro- DMs help more than micro-and macro-DMs together and more than micro- DMs alone in L2 learners' understanding and recall of lectures. In several studies inspired by Chaudron and Richards (1986), the positive effects of the

ExLing 2008: Proceedings of $2^{\text {nd }}$ Tutorial and Research Workshop on Experimental Linguistics, 25-27 August 2008, Athens, Greece 
presence of DMs in texts (Flowerdew and Tauroza, 1995; Williams, 1992; Zohreh and Rasekh, 2007) are shown although some indicated that DMs do not assist L2 listeners in comprehending English-medium lectures (Dunkel and Davis, 1994).

\section{Problem}

ELT students in their English medium classes in the Turkish educational setting are usually exposed to various complicated lectures in L2 and need to decode them on their own. As revealed in informal interviews and observations, ELT students frequently want their teachers to retell or summarize what is told in their mother tongue at the end of the classes, which confirms they have difficulties and need to construct effective strategies in listening to lectures in L2. Listening efficiently in L2 is a difficult task that requires very careful observations and intelligent strategies on the part of the listener. It may be helpful for students to be provided with additional discourse-based strategies to aid their listening comprehension. Therefore, the probable effects of DMs on students' L2 listening comprehension are investigated in the present study as it is believed that such an awareness is an essential part of understanding spoken discourse. Listening to computer speech was also included in the design to see whether computer speech can offer comprehensive discourse where DMs play a role. This study aims to answer the following research questions: 1) Do DMs play a role in L2 listening comprehension? 2) Do software programs of listening make a difference in L2 listening comprehension?

\section{Methodology}

As instruments to measure listening comprehension, two different versions of three texts [Artificial Life, The Cypriots, and Divorce and Kids] (Kiymazarslan et al., 2005) were used: one with very few micro markers and the other with macro markers in addition to few micro markers. The selected talks had very few DMs in nature. Macro DMs were added later and were revised for their information structure and authenticity. Two sections in the department were taken as the Groups A and B. At different times, Group A listened to the talks with few micro DMs while Group B listened to the version with macro markers read by the computer, by a native speaker or a non-native speaker. Thus, two groups of approximately 25 freshman students (50 in total; 47 females, 3 males) aged between 17 and 23 listened to two versions of three different talks with and without higher order DMs. The listeners heard the talks via two loudspeakers during their regular class hours in an electronic classroom. They listened to the talks twice. In the delivery of the talks via computer, a computer program "NaturalReader@ 7.0" was used to convert written talks into spoken words. The written 
comprehension scales (three different tests) contained five-item YES/NO questions $(\mathrm{r}=0,76)$. A Mann-Whitney $\mathrm{U}$ Test was used to compare the means of the groups.

\section{Results}

The presence of macro DMs was found to be statistically significant only in native speaker talk $(\mathrm{p}<0,05)$. With macro DMs, a remarkable increase at comprehension levels was also seen in computer talk, but it was not statistically significant. The use of DMs in non-native speaker talk did not affect comprehension levels significantly. The highest mean score of comprehension was obtained from the talk with micro and macro DMs delivered by the native speaker. The software program ranked second in providing comprehensive talks when they contain micro and macro DMs. (Figure 1).

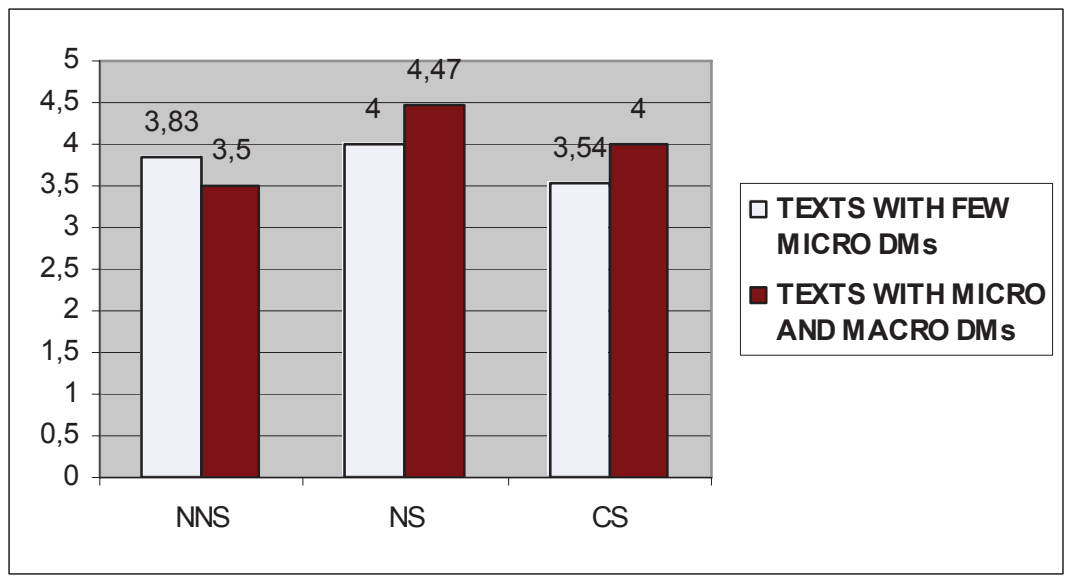

Figure 1. Comprehension Levels in L2 Listening. (NNS: Non-Native Speaker, NS: Native Speaker; CS Computer Speech).

\section{Conclusion}

The findings of this research contributed to the idea that macro-DMs led to better recall of the lectures than lower level markers, micro-DMs. However, macro DMs are seen to play a significant role only in native speaker speech. This is quite reasonable since the listeners could make use of the native speaker's signals of major segments or transitions that probably add an organizational effect to the talks, which make the information more salient and meaningful. Native speaker's intonation and emphasis on major segments seem to help listeners. 
Secondly, probably because of prosodic problems, the presence of DMs in computer speech did not play a significant role in comprehension. This suggests such software programs may work better in listening laboratories in case they should be improved in speech prosody as poor prosody can distract the listener and impede comprehension.

\section{Acknowledgements}

I owe gratitude to Dr. Laurence Raw and to my freshman students (IDO Sections $1 \& 2$ ) for their valuable contribution to the study in the data collection process.

\section{References}

Brown, G and Yule, G. 1985. Discourse analysis. Cambridge: Cambridge University Press.

Chaudron, C and Richards, J.C. 1986. The Effect of Discourse Markers on the Comprehension of Lectures. Applied Linguistics. Vol.7 No. 2. 113-127.

Dunkel, P. A. And Davis, J. M. 1994. The effects of rhetorical signaling cures on the recall of English lecture information by ESL and ENL listeners. In J. Flowerdew (Ed.), Academic listening: Research perspectives (pp. 55-74). Cambridge: Cambridge University Press.

Flowerdew, J. and Tauroza, S. 1995. The effect of discourse markers on second language lecture comprehension. Studies in Second Language Acquisition, 17, 435-458.

Kiymazarslan,V; Alagözlü, N. and Mirzayeva, N. 2005. Interactive Listening Booth. For Listening Practice. Seçkin Yayıncılık. Ankara.

Shiffrin, D. 1992. Approaches to Discourse. Blackwell. Oxford.

Williams, J. 1992. Planning, discourse marking and the comprehensibility of international teaching assistants. TESOL Quarterly, 25(4), 693- 708. Zohreh R. E. and Rasekh A.E. (2007) Discourse Markers in Academic Lectures. Asian EFL Journal. Volume 9, Issue 1. 